\title{
Rethinking the Hospital Pharmacist Service: Centralized Logistics- Ict Systems and Clinical Pharmaceutical Care Strategies as a Management Opportunity for Public and Private Institutions
}

\author{
Luisetto $\mathbf{M}^{*}$ \\ Public Hospital Pharmacist Manager, Applied Pharmacologist, Italy
}

Submission: September 25, 2017; Published: October 04, 2017

*Corresponding author: Luisetto m, Public Hospital Pharmacist Manager, Applied Pharmacologist, European Specialist in Lab, Italy, PIACENZA AREA 29121, Email: maurolu65@gmail.com

\begin{abstract}
In last year's healthcare costs are increased constantly in logarithmic way and this conditions need an high efficiently resource management system more than past. Drugs, medical devices, diagnostics or medical errors are relevant voice in the public and private hospital current budget and healthcare Institution and government tray every day to control it. (U.S. HEALTH national expenditure amounted total 3.0 -3billion U.S. D. The total spending on medicine in the USA was about 6 more than 400 us dollars in 2015).An high performance HEALTHCARE org. Need today: deep innovations, right management of materials (LOGISTICS drugs and medical devices use), new technologies knowledge, risk management skills and other resource.
\end{abstract}

Keywords: Change management; Hospital pharmacy; Innovation; Strategy; Healthcare; Pharmaceutical care and Clinical pharmacy; Logistics; Medical error; Clinical outcomes

\section{Introduction}

Strategic, change, knowledge management approach, sharing economy philosophy and other new instruments as velocity management [1] gives improving the global results. (Economic but also clinical). Also Multi-professional medical equip with permanent presence of the clinical pharmacists give improving in global results (clinical - economic outcomes) [2]. Risk management Reduce total costs due by therapy and other kind of error And gives solution to related problems in preventive and proactive way. The clinical pharmacists complete the patient medical team Adding deep pharmaceutical and pharmacological competencies (To prevent ADR, therapy errors, and monitoring the PHARMACOLOGICAL therapy) resulting in more containing in medical error. Inefficacy HR management gives high contributed in the TOTAL results [3] make possible rapid introduction of the different healthcare professionals in EQUIP.

But Today we have also a powerful instrument to efficacy control the costs to be used: centralized logistics systems (to reduce GLOBAL costs of drugs and medical device). The centralized logistic (and regional buying center) make possible a great rationalization in costs and in hospital pharmacy working time.
This system Increase the AMOUNT of orders (Cumulative way) and this make possible to have more discount in drug prices by pharmaceutical industries. The ordering by the different hospital linked and associated in this way this contribute to containing total costs more versus without this strategy. More over This make possible reduce hospital pharmacy stokes (immobilized drugs costs, less expiration data problems) giving the same time continuity to the therapy to the hospital wards in safety way. This systems need a just in time systems and a great support by ICT (healthcare professionals with informatics and data management knowledge.)The rapid communication with the hub and spoke make possible To have the drugs in strictly time.(we can think to saving life drugs especially).The hosp. pharmacist clinical competences gives the correct priority (in ordering procedure) and this is a crucial fact in the global management of the systems.

With centralized logistic need a small stoke of drugs in the hospital pharmacy whit 60-80 kind of molecules (critical medical devices and drugs) and an emergency ICU Drugs Cabinets to cover emergencies (if not ACTIVE an h24 hospital pharmacist service.) The great amount of drugs and medical devices are stoked in central ware house. This approach needs 


\section{Juniper Online Journal of Public Health}

high expertise by the clinical hosp. pharmacist To rationalize the systems without error: right classification of critical drugs and an efficacy risk management system to prevent dis- functions (root cause analysis, FMEA approach, total quality management and other strategy). We can say that the clinical pharmacists works must be an edge between ward the hosp. pharmacy and the hub. (ICT mediated). Other instrument to manage at the right level can be Dose unit drug systems, informative prescription with applied software, oncologic unit's sterile robot, emergency drugs cabinet systems and some other. All this rationalize the hospital global request of drugs and med devices but also reduce in high way therapy error. ICT technologies provide scurrility system to transfer patient and other data. The total knowledge is increased using these ICT systems. (Biomedical database for prevent interactions, contraindications and other).

But what is relevant in this new process is the active role of hospital clinical pharmacist in more consultant activity versus the classic logistic Functions. (A cultural changes) from the classic logistic function towards more clinical new pharmaceutical consultant functions. This make possible in the same time to adequately monitoring the healthcare costs (drugs and med. devices) containing medical and therapy error, improving also the clinical outcomes [2]. The application of clinical pharmacist presence in stabile way in medical team results in about $35 \%$ cost reduction (drugs, med dev.), costs due by medical errors, reducing recovery days. In example, an Italian practical experience: health ministerial project: "Ward clinical pharmacists in oncology"[29]. A collaboration of: SIFO (Italian Society Hospital Pharmacy), Italian Federation of professional Pharmacists' Orders, Italian assoc. Of Medical Oncology), EAHP (European Association of Hosp. Pharmacist), a multi-center experience involving 5 public hospitals with the presence of clinical pharmacists in the oncology wards. The result was a reduction of ward drug and MD stokes from 32\% to $88 \%$ and $30 \%$ less of drugs therapy errors [29].

Related to these results. The managerial competences and skills and knowledge of the clinical pharmacist are often requested by general manager office and by physician's director of the many discipline to monitoring and control the global buying systems [5]. Antimicrobial stewardship [7] , med. Gases pharmacy management, high cost drugs management, medical dev.high competencies, Toxicological equip with hosp. pharmacists presence, oncology lab ,ICU, nutrition team service , pain management medical equip , and other involving clinical pharmacist create an high synergy. Other relevant role can be played in surgery field [23] nephrology, heart disease and many other .In ex. the total cost for innovative drug therapy are under an high increase (therapy of hepatitis c ) , antimicrobials meet great resistance, oncology therapy do not present equal efficacy towards all neo plastic tissue the same."The economic aspect is relevant on cost of drugs and payment by government and institution or insurance. (In example 35.000 euro/USD/ patient for some biological MABS).Even ministry of health in some countries (ITALY) not pay all some new innovative drugs but use a system that verify the results obtained. (Payment by results or risk sharing et other procedure)" [6]. This problems need a deep and continuous high activity by clinical pharmacist to create a more rational decision making systems in today therapy world.

\section{Material and Methods}

In this observational and research work we report some relevant publications ( in our opinion ) involved in this change and related to the results we have find we submit to healthcare institution a new systems to efficacy control and reduce the healthcare costs improving clinical outcomes.We observe the hospital pharmacy organization in different countries in order to verify The organizational way of works .We describe also a practical research experience involved in management of emergency drug in hospital setting [24]. Then after this research we analyze the total costs involved in this kind of organization change and the advantages that can be obtained.

\section{Results}

Observing the hosp. pharmacy organization in many countries we can say that the pharmacy service is more oriented to the classic function as logistic, galenic lab, nutrition lab, dispensing activities and other.

But only few hosp. pharmacy service are highly oriented to advanced clinical function as advanced center usually do the same the university course involved in hospital pharmacy are more focused on the classic pharmacist function and only in recent decades towards more clinical Functions.(only few cases really involved in improving the clinical outcomes in medical team and not only with monitoring tasks). Also technology applications are not equally available to all hospital places. (Small - large hospitals, rural or city et other). From literature we have find this results: "During 1930 to 2016 a progressive development of clinical pharmacy and pharmaceutical care was developed. We have observed a "general positive influence of the pharmacist's presence as a part of the medical equip, on public health in various clinical outcomes"; this according to systematic reviews, clinical trials and meta-analysis" [8]. "The model of clinical pharmacy practice adopted by many pharmacy department hospitals is no longer appropriate for the demands of today's health-care services. Reviews many new models proposed for clinical pharmacy practice including an integrated model for providing a pharmaceutical care management approach in the health-care system. This model is a response to the failures of traditional drug and pharmacological therapy.

It is an idea about how health professionals should integrate their professional work to obtain clinical outcomes important to patients and clinicians" [9]. "Hospital information system is widely used to improve efficiency of china hospitals. A novel clinical pharmacy management system developed by our hosp. was introduced to improve work efficiency of clinical pharmacists, by providing pharmacy information services and promoting 
rational pharmacological drug use. Taking prescription review in the dep. of surgery, work efficiency of clinical pharmacists, quality and qualified rates of prescriptions before and after utilizing clinical pharmacy management system were compared. Qualified rates of both the inpatient and outpatient prescriptions of the general surgery department increased, antibiotics use decreased. This system apparently improved work efficiency standardized the level and accuracy of drug use, which will improve the rational drug use and pharmacy info service in our place. The utilization of prophylactic antibiotics for the aseptic operations reduced" [10].

"Clinical Pharmaceutical Care "as a new discipline, to improve clinical and economic endpoint in pharmacological therapy reducing therapy errors with a more rational use of resource in medical team. This new approach take advantages by Management discipline and ICT principles. Core training must include Management, ICT new social media, psychological behavior and other skills and attitudes for team working added to the classic clinical pharmacy core programs. The knowledge in field of diagnostic discipline gives great advantages in this field for the high relationship with much drug therapy [11]. "Based on the results of this study, the observed achievements were due to medical lab.

And imaging knowledge and competencies of the clinical pharmacist, as part of the equipe in a hospital setting. Such expertise of the clinical pharmacist has resulted in a significant impact on therapy. For patients' safety and health and cost reduction and for clinical pharmaceutical care purposes, it is incumbent upon the hospitals to engage and demand an active role from clinical pharmacists, especially in fields such as diagnostics (med. Lab. and imaging) [12]. "to obtain more efficient results in improving some clinical outcomes the clinical pharmacist must have an expert skill in the field of psychological and behavior aspects to use a practical settings when member of medical team .Rotation in different wards provide a a real good experience. This skill and attitudes is useful in pharmacistspatients' relationship in order to have high patient's compliance level..." [13]. Reduction of medication therapy errors is needed and demanded by: patients, health authorities, government, insurances companies. "Multi professional healthcare team is the right way of work in health care today. A WARD clinical pharmacist today contributes in many fields: hematology oncology, toxicology, infectious diseases, emergency med., nephrology, nutrition pharmacy service, pain management and others" [11].

The clinical endpoints depend also by the med. device used and pharmacist specialist represents a great resource in cost containment in every level (to use the right one in every different situation) in this specific use. Ph. care principles can correctly be applied in themed. Devices dedicated to the single patient. Consultant activities in properties, classification, legislation, Alternative products, logistic are the working filed in which hospital pharmacist play a relevant roles in medical equipe"
[14]. "The innovation introduced with biomed. Databases and searching engine motors improved research works with rapid ways in all kind of scientific areas Internet, and professional social media have brought a great development in rapidly connecting with professionals. The researchers in last 3 decades has been great possibility to share their practical experience more than past with improving results.

They are playing a crucial and relevant role today working field through this rapid development. LinkedIn, Slide share, Research gate, Pub Med, you tube NCBI, Facebook, and other etc. The possibility to create new bridge researchers; with similar interests, discipline with more rapid development, never seen in last 3 decades" [15]. "In ICU we can see reduction in mortality rate when pharmacist takes really part of the equip. [12]. "Clinical Ph care required more use also of social media to meet researcher in more efficient way. In the same time clinical pharmacist can be a scientific edge between professional in therapy filed. PH care management can be useful tools to have more rational therapy systems.

Drugs are registered for specifically indication, and at the same time every drug to be a rational therapy need a rational decision making system that require a multidisciplinary equipe that can cover all aspect of Pharmaceutical and pharmacological molecular metabolism (also kinetics andPharmacodynamics) this have great possibility for clinical pharmacist but it must increase expertise in field of diagnostic (lab medicine and imaging) for the high relationship whit pharmacological drug therapy. The old algorithm was "physicians - patients - classic pharmacist and drugs "today it must be "patient physicians clinical pharmacists (as consultant) and drug [16].

"Physicians alone cannot cover all aspect of the pharmacological treatment (for example in the field of drug therapy monitoring, interactions, adverse drug reaction ADR, toxicology, novel delivery systems, immune globulin-based) therapeutics and other innovative drugs and medical devices systems, which have their pharmaceutical specific worlds. This article likes to improve the ph. care application in countries with an advanced healthcare system to provide more rational drug therapy to patients. When not possible, it would be a good idea using ph. care, in particular populations such as: severe disease, critically ill, patients with multiple illnesses, transplants, immunosuppressant, oncology or other serious conditions, at least when the treatments cost a lot" [2]. Using sharing economy instruments we can reduce healthcare costs about $38-40 \%$ and obtain this results in more rapid way. The results obtained with sharing economy time can be applied in healthcare: sharing of knowledge"ICT systems can reduce errors and waste materials, rotation drugs and med. devices stokes and reducing costs: Dose unit systems and programs reduce costs about $10-15 \%$ and ward clinical pharmacist presence in stabile way in medical team can reduce cost about 25-30\%." (8)In a lancet infection disease meta-analysis was reported" Our findings of beneficial effects on outcomes with nine antimicrobial stewardship objectives 
suggest they can guide stewardship teams in their efforts to improve the quality of antibiotic use in hospitals [17].

According to last editorial The Clinical Pharmacists Main Focus. J Appl Pharma 9: e114 we can see that one of the main focus of the clinical pharmacist "must be applied in priority way to the most critical patients in order to achieve the best results available [12]. In this condition even benefit of 1 life achieved in mortality rate is a real golden endpoint (we can think for example to a pediatric poisoning, or severe infectious disease in pregnancy or the effect of inefficacy immunosuppressive therapy in transplanted et other) [13]. This can be considered in example as reduction in NNT to improve a therapeutic strategy" [18].

We have also see in some practical experience that the introduce in daily works of some technologies make possible a right management (reducing total costs and with safety) in example in emergency drug cabinet systems [7] "no near miss event or other patient risk or even fatal event was observed and was covered the the emergency need of drugs in the $99 \%$ of cases, and only 1 time was necessary the central pharmacy call." (The same results we have observed during One year), we can have also a reduction in total costs providing an efficacy system . ( about 50.000 euro in 5 years in an Italian public hospital 700 beds) [24]. Other ICT instruments are in examples dose unit system to provide single Unit of drugs (preventing waste or expiration of pharmacological therapies- full therapy traceability), informatics prescription software (to detect interactions, allergy, toxicity ),Informatics management of narcotic drugs or antidotes for right logistics and other.

\section{Discussion}

Analyzing the literature reported in this work and the results of a specific practical experience $[24,28]$ we can say that using drugs central logistics (hub and spoke pharmacy system) added to ICT instrument and clinical pharmaceutical care and amore clinical pharmacy approach we can have reduced costs about $40 \%$.This result not only due by drugs and med. devices costs rationalized but also by the reducing of med. errors, days of recovery and especially by improving clinical outcomes. In example the costs for an expensive transplant can be lost easy if not applied efficacy pharmacological drug therapy .(the same thinking about complex cardiac surgery or other critical and expensive patients situation).The pharmacist competences/ skills added to ADVANCED ICT INTRUMENTS can improve the global clinical results. This is the reason to shift from the classic logistic competences and skills of clinical pharmacist towards more and deep clinical tasks and to make an intensive ICT use as requested today.

\section{Conclusion}

We think that this kind of change in pharmaceutical dep. is today needed and this shift of hosp. pharmacist competence from the classic logistic roles towards more clinical /economic management tasks.gives reduction of $35-40 \%$ in healthcare total costs The application of clinical pharmacist to strictly control the prescription of drugs an M .DEV. (according protocols, guidelines, central - local rules ) make possible an great appropriateness verify $[17,18]$. We think that the efficacy instruments to the clinical pharmacist and healthcare institution to manage healthcare costs can be:

a) Management principles and TQM

b) Clinical Pharmaceutical care (new health care discipline) [19]

c) ICT technologies

d) Sharing economy principles of applications

The total costs involved in this change in working activities of hospital pharmacist are included in the costs rationalized by this new management system. (we can say that is not a cost but a resource.)Pharmacy must be considered not only like a definite fiscal place but a complex world where the consultant clinical activities can make the difference in patient outcomes (clinical, economic, quality of life)The core process must be a rethinking in hospital pharmacy competences enhancing the clinical competences level and time dedicated to this specific tasks. This kind of process must involve politics stakeholders institution, healthcare org., decision making hospital general managers, universities and the same all healthcare Professional [20-25].

The principal goal is obtained if this change is accepted by all. The actors and professionals involved in healthcare management agree with this new approach. But is crucial that the same hosp. pharmacist know that in this new organization system other specific kind of responsibility are involved in direct patient clinical pharmacy and pharmaceutical care works. The experience we have see [7] can be usefully transferred to other hospital and other situations giving good results [26,27].

\section{References}

1. Luisetto M (2016) Velocity Management Strategy in Healthcare. Journal of Business \& Financial Affairs 5(4): 1-2.

2. M Luisetto, F Carini, G Bologna, B Nili Ahmadabadi (2015) Pharmacist Cognitive Service and Pharmaceutical Care: Today and Tomorrow Outlook. Journal of Pharmaceutical and Biosciences 3(6): 67-72.

3. Mauro luisetto (2017) Attitudes and Skills in Business Working Settings: A HR Management Tool. Bus Eco J 8(1).

4. Luisetto M, Nili-Ahmadabadi B (2017) The Clinical Pharmacist Competence as Pharmaceutical Drug Design Tool. J HospClinPharm 3: 7-10.

5. Luisetto M (2016) Editorial Clinical Pharmaceutical Care and New Technologies: A Synergy to High Reduce Healthcare Costs. J Bus Fin Aff 5: 3.

6. Mauro luisetto (2016) Editorial Efficacy of Oncologic Drug Therapy: Some to rethink in the Management of the System. Journal Of Business Management And Economics 1:1.

7. Luisetto M, Nili-Ahmadabadi B, Mashori GR (2017) The Clinical Pharmacists Main Focus. J Appl Pharm 9: 114. 
8. M Luisetto, B Nili Ahmadabadi, L Cabianca, M IbneMokbul (2016) Steps and Impacts of Pharmaceutical Care and Clinical Pharmacy Development on Clinical Outcomes 2016: A Historical Analysis Compared with Results. Clinicians Teamwork 1: 4-8 .

9. al-Shaqha WM1, Zairi M (2001) Pharmaceutical care management: a modern approach to providing seamless and integrated health care. Int J Health Care QualAssurInc Leadersh Health Serv 14(6-7): 282-301.

10. Bao L, Wang Y, Shang T, Ren X, Ma R (2013) A novel clinical pharmacy management system in improving the rational drug use in department of general surgery. Indian J Pharm Sci 75(1): 11-15.

11. Luisetto M (2016) Nuclear Medicine: A Synergy to Improve Clinical Outcomes and Reducing Costs. Medical Laboratory Imaging, Clinica Pharmaceutical Care J App Pharm 8: 3.

12. Nili Ahmadabadi, M Luisetto, H Nili Ahmadabadi, H Nasser, GR Mashori, et al. (2016) Clinical Impact of Pharmacist Presence in ICU Medical Team on MortalityRate. Clinicians Teamwork 1: 15-33.

13. Luisetto M (2016) Psychological and Behavior skills for Ph. care practice in medical team. IJPPR 5 p. 1-4.

14. Luisetto M (2016) The Medical Devices Pharmacists Management Role and Pharmaceutical Care. L J App Pharm 8: 3.

15. Luisetto M (2016) Professional Social Media: Instrument to Meet Researcher and Healthcare Instruments with a Model for a New Scientific Social Network . Int J Econ Manag Sci 5: 3.

16. Luisetto M (2016) An Useful Instrument in Future Health Care Systems. J Pharma Care Health System.

17. Luisetto M, R Sahu (2016) Clinical Pharmaceutical Care A New Management Health Care Discipline in 2016. UK Journal of Pharmaceutical and Biosciences 4(1): 63-64.

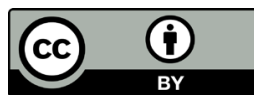

This work is licensed under Creative Commons Attribution 4.0 Licens DOI:10.19080/JOJPH.2017.02.555589
18. Schuts EC, Hulscher ME, Mouton JW, Verduin CM, Stuart JW, et al. (2016) Current evidence on hospital antimicrobial stewardship objectives: A systematic review and meta-analysis. Lancet Infect Dis 16: 847-856.

19. Luisetto M, Nili-Ahmadabadi B, Mashori GR (2017) The Clinical Pharmacists Main Focus. J Appl Pharm 9: 114.

20. Luisetto M (2016) Management Instrument in Pharmaceutical Care and Clinical Pharmacy sciences. Int J Econ Manag Sci 5: 5.

21. M Luisetto, B Nili Ahmadabadi (2016) An Open Letter to all Pharmacists : Pharmaceutical Care 1:1-3.

22. Medical Laboratory and Imaging. Clinicians Teamwork 1: 1-4.

23. Luisetto M (2016) Pharmaceutical Care in Surgery Field editorial. J Pharma Care Health Sys 3: 3.

24. Luisetto M, Nili Ahmadabad (2016) Review article: Emergency Hospital Drug Cabinet Systems Managed by Hospital. J App Pharm 8: 4.

25. Mauro Luisetto (2017) New Theories in Management Decision Making Systems. SF Journal of Intellectual Property Rights 1: 1-7.

26. Luisetto M (2016) Pharmaceutical care and toxicology: a synergy in high risk situation. J Appl Pharm 8: 1-7.

27. Luisetto M, Nili-Ahmadabadi B (2017) The Clinical Pharmacist Competence as Pharmaceutical Drug Design Tool. J Hosp Clin Pharm 3: 7-10.

28. poster abstract sifo congress 2016 the emergency drug hospital system : l'armadio delle urgenze gestito dal Farmacista Ospedaliero Atti del XXXVII Congresso Nazionale SIFO Milano, 14 dicembre 2016 Confalonieri C. Luisetto $\mathrm{m}$ et a

29. Il Farmacista di Dipartimento quale strumento per la prevenzione degli errori in terapia e l'implementazione delle politiche di Governo clinico in ambito oncologico 2011 ministero della salute it

\section{Your next submission with Juniper Publishers will reach you the below assets}

- Quality Editorial service

- Swift Peer Review

- Reprints availability

- E-prints Service

- Manuscript Podcast for convenient understanding

- Global attainment for your research

- Manuscript accessibility in different formats

( Pdf, E-pub, Full Text, Audio)

- Unceasing customer service

Track the below URL for one-step submission https://juniperpublishers.com/online-submission.php 